\title{
One-Hour Training for General Practitioners in Reducing the Implementation Gap of Smoking Cessation Care: A Cluster-Randomized Controlled Trial
}

\author{
Marjolein E. A. Verbiest $\mathrm{MSc}^{1}$, Mathilde R. Crone $\mathrm{PhD}^{1}$, Margreet Scharloo $\mathrm{PhD}^{2}$, Niels H. Chavannes $\mathrm{MD} \mathrm{PhD}^{1}$, \\ Victor van der Meer $\mathrm{MD} \mathrm{PhD}{ }^{1}$, Ad A. Kaptein $\mathrm{PhD}^{2}$, Willem J. J. Assendelft $\mathrm{MD} \mathrm{PhD}^{1,3}$ \\ ${ }^{1}$ Department of Public Health and Primary Care, Leiden University Medical Centre, Leiden, The Netherlands; ${ }^{2}$ Department of \\ Medical Psychology, Leiden University Medical Centre, Leiden, The Netherlands; ${ }^{3}$ Department of Primary and Community Care, \\ Radboud University Nijmegen Medical Centre, Nijmegen, The Netherlands
}

Corresponding Author: Marjolein E. A. Verbiest, MSc, PhD Candidate, Department of Public Health and Primary Care, Leiden University Medical Centre, PO Box 9600, 2300 RC Leiden, The Netherlands. Telephone: +31-71-526-5761;

Fax: +31-71-526-8259; E-mail: m.e.a.verbiest@lumc.nl

Received February 25, 2013; accepted June 14, 2013

\begin{abstract}
Introduction: This study examined the effectiveness of low-intensity, practice-tailored training for general practitioners (GPs) aimed at personal and organizational barriers that arise when routinely asking patients' smoking status, advising to quit, and arranging follow-up.

Methods: A cluster-randomized controlled trial with 49 GPs and 3,401 patients (677 smokers). Two patient groups participated: 2,068 patients (433 smokers) at baseline and 1,333 patients (244 smokers) postintervention. At follow-up, 225 smokers of both groups participated. The primary outcome was GP smoking cessation counseling (asking about smoking status, advising to quit, prescribing pharmacotherapy, and referring for behavioral support). Secondary outcomes were GPs' attitudes toward smoking cessation care, patients' intention to quit, and long-term quit rates. Outcomes were measured with GP self-report and patient report.
\end{abstract}

Results: Patients of trained GPs reported more often being asked about smoking behavior compared to patients of untrained GPs $(O R=1.94,95 \% C I=1.45-2.60)$. According to GP self-report, the training increased the provision of quit-smoking advices (difference 0.56 advice per day; $95 \% C I=0.13-0.98$ ) and the ability and intention of providing smoking cessation care. We found no effect on GPs' arrangement of follow-up, smokers' intention to quit, and long-term quit rates.

Conclusions: After 1 hour of training, we found significant differences between trained and untrained GPs on the frequency in which they asked about smoking (patient reported) and advised smokers to quit (GP self-reported). The training did not increase prescriptions of pharmacotherapy, referrals to behavioral support, or quit rates. Future training methods should focus on the GPs' ability, tools, and skills to arrange follow-up to ensure intensive smoking cessation support.

\section{INTRODUCTION}

General practitioners (GPs) play a key role in the delivery of smoking cessation interventions to their patients. Even a GPs' minimal intervention of advising smokers to quit has the potential to significantly benefit smokers' motivation to quit and smoking abstinence (Pieterse, Seydel, de Vries, Mudde, \& Kok, 2001; Stead, Bergson, \& Lancaster, 2008). Guidelines recommend that GPs put into practice a systematic approach of asking every patient about tobacco use, advising all smokers to quit, assessing smokers' willingness to make a quit attempt, assisting smokers with treatment and referrals, and arranging follow-up contacts (5-A model; Chavannes et al., 2007; Fiore et al., 1996, 2008; Puschel et al., 2008; Segaar, 2009; Stop
Smoking Partnership, 2009; Takahashi et al., 2006; The Royal Australian College of General Practitioners, 2011). In spite of the well-documented effectiveness of these guidelines (Pieterse et al., 2001; Puschel et al., 2008; Takahashi et al., 2006), many GPs fail to routinely implement them (de Korte, Nagelhout, \& Willemsen, 2010; de Korte et al., 2010; Quinn et al., 2005). This results in a substantial evidence-practice gap.

Several factors may affect the implementation of smoking cessation care (SCC) in general practice, related to the health professional and the organization (Crone et al., 2006; Fleuren, Wiefferink, \& Paulussen, 2004). Personal barriers of GPs that impede the implementation of tobacco support are doubts and concerns regarding their ability to deliver SCC, and the effectiveness and the appropriateness of SCC 
(Djalalinia et al., 2011; Stead, Angus, Holme, Cohen, \& Tait, 2009; Twardella \& Brenner, 2005; Vogt, Hall, \& Marteau, 2005). Also, organizational barriers may hamper guideline implementation, as GPs often report role confusion, time, and financial constraints (Vogt et al., 2005). For this reason, interventions aimed at enhancing the implementation of SCC guidelines should be multifaceted and tailored to the needs of the health professional and organization (Baskerville, Liddy, \& Hogg, 2012; Harris, 2008; Oxman, Thomson, Davis, \& Haynes, 1995; Stead et al., 2008, 2009; Tremblay et al., 2001; Zwar \& Richmond, 2006).

Training health professionals in improving SCC has been shown to benefit the implementation of counseling tasks, such as asking patients to set a quit date and providing selfhelp materials, as well as patient smoking abstinence (Carson et al., 2012). However, these training programs often fail to address organizational constraints that impede full implementation of smoking cessation guidelines (Carson et al., 2012). Since smoking cessation counseling varies widely between general practices (Ellerbeck, Ahluwalia, Jolicoeur, Gladden, $\&$ Mosier, 2001), strategies are needed that address the specific constraints GPs deal with in order to maximize the implementation of smoking cessation support and patients' smoking abstinence rates.

Therefore, we developed and examined the effectiveness of a new low-intensity, practice-tailored training method aimed at improving smoking cessation counseling activities of GPs. This method is tailored to the personal and organizational barriers that arise during the implementation of SCC in regular daily practice. In the present study, we focus on the implementation of routinely asking patients' smoking status, advising smokers to quit, and arranging follow-up. This simplified approach (also called the A-A-A approach) has recently been introduced in health care settings where professionals face insurmountable barriers, such as a lack of time to provide assistance to smokers who want to quit (Berndt et al., 2013; Vidrine et al., 2013). Because preventive tasks, such as intensive lifestyle counseling, are more often delegated to the practice nurse within Dutch general practice, this simplified approach is a promising solution to reduce the implementation gap of SCC in general practice.

We hypothesize that our training method will increase GPs' smoking cessation counseling activities, especially the rate at which smokers are identified, advised, and referred. Since we focus on the implementation of GPs' minimal cessation intervention, we expect a small but significant effect on smoker's intention to quit. If trained GPs succeed to increase the rate at which smokers are referred to intensive cessation support, we expect higher rates of long-term smoking abstinence reported by patients of trained GPs.

\section{METHODS}

\section{Design}

We performed a cluster-randomized controlled trial in general practice. In order to account for a lack of independence between the patients of the same GP, the GP was the unit of randomization. GPs were matched according to gender, age, and practice type and randomly assigned to one of the two conditions using a simple randomization procedure (coin tossing) by an independent researcher not involved in the recruitment of the GPs. Patients were unaware of the allocation during the entire study period. GPs remained unaware about the allocation until after the baseline measurements; thereafter, the GPs were informed about the allocation. GPs in both conditions were aware of the aim of the intervention during the entire study period. The study was approved by the Medical Ethical Board of the Leiden University Medical Centre (P10.125).

\section{Intervention}

We earlier conducted a systematic review on the effectiveness of training health care professionals in SCC (Carson et al., 2012). The results of this meta-analysis show that a single, short training session is likely to be just as effective as multiple longer sessions. Therefore, we developed a single, 1-hr training session in order to anticipate time constraints GPs often face. The GP training was delivered by a certified trainer of the Dutch Expert Centre on Tobacco Control (STIVORO) and was based on the 5-A behavior change model from which we derived the 6-I model (Fiore et al., 1996, 2008); an inventory was made of GPs' current knowledge and skills as well as organizational and personal barriers regarding SCC and the GP was informed about the effectiveness of SCC in general practice. GPs' motivation to implement SCC was identified and less motivated GPs were inspired using motivational interviewing techniques, such as exploring and resolving ambivalence (Rollnick \& Miller, 1995). GPs were instructed on knowledge and skills related to the barriers they indicated. Several themes could be addressed, such as the content of the SCC guideline, behavioral and pharmacological SCC support, skills in motivating smokers to quit, and organizational aspects of SCC, such as task allocation, referral, and registration. The training concluded with concrete, individual implementation goals that were summarized into an action plan. In addition, all GPs received a toolkit, which contained a SCC flowchart, a summary of pharmacological support, and leaflets for patients. Afterward, the GP was given the opportunity to receive additional feedback support (intervision). GPs in the control condition continued their usual SCC. Usual care can be defined as the SCC that is usually provided by the GP when not being trained, which is likely to vary between the GPs (Ellerbeck et al., 2001).

\section{Participants}

\section{General Practitioners}

We recruited GPs by letter and a follow-up telephone call. Eligibility criteria were the self-reported number of provided stop-smoking advices per week (maximum of five; Koolhaas, 2005), in order not to select "best-practice" GPs only. In addition, we selected only one GP per practice in order to prevent contamination. Among 228 GPs who returned the screening questionnaire, 64 agreed to participate. Six GPs were excluded because they provided on average more than five stop-smoking advices per week, and another nine GPs already had a participating colleague in the same practice; this resulted in 49 GPs for randomization. After randomization, 4 GPs (3 intervention and 1 control) were partly excluded from further analyses because they did not complete their measurements, 
leaving 45 GPs for full analysis (22 intervention and 23 control).

\section{Patients}

During the study period (January-August 2011), adult patients visiting participating GPs in both conditions were asked to complete a questionnaire after consultation. The baseline group consisted of 2,068 patients (1,002 intervention and 1,066 control) including 433 smokers (195 intervention [19.5\%] and 238 [22.3\%] control) who completed the questionnaire during the 3 weeks prior to the GP training. The postintervention group consisted of 1,333 patients (630 intervention and 703 control), including 244 smokers (98 intervention [15.6\%] and 146 [20.8\%] control) who completed the questionnaire during the 3 weeks after the GP training. All smoking patients of both the baseline and postintervention group were sent a postal questionnaire 9 months after the intervention, which was completed by 225 smokers (112 intervention [response rate $38.2 \%$ ] and 113 control [response rate $29.4 \%$ ]) (Figure 1).

\section{Outcomes}

The primary outcome was GP smoking cessation counseling. Secondary outcomes were GPs' attitudes, self-efficacy and intentions toward implementing SCC, and patients' intention to quit and long-term smoking abstinence.

\section{GPs' Smoking Cessation Counseling}

We measured GPs' smoking cessation counseling by means of GP self-report and patient report. At baseline, GPs in both conditions completed a tracking list at the end of two working days per week, during three consecutive weeks. Questions were about smoking cessation activities during that day (asking, advising, prescribing pharmacological aids, and referring for behavioral support). In the intervention group, GP training in SCC took place within 2 weeks after this first tracking period. One week after the training, a second tracking period started for GPs in both conditions. On those days that GPs completed the tracking lists, all adult patients who visited the participating GPs were asked to complete a questionnaire after consultation. These questionnaires included information on sociodemographics and GP performance with regard to SCC.

\section{GPs'Attitudes, Self-Efficacy, and Intention Toward \\ Implementing $S C C$}

Secondary endpoints were GPs' attitudes, perceived self-efficacy, and intentions regarding routinely implementing SCC, measured with a pre- and postquestionnaire based on previous studies (Drossaert, Pieterse, Seydel, \& Drenthen, 1999; Mudde, Willemsen, Kremers, \& de Vries, 2000; Pieterse et al., 2001).

\section{Patients'Smoking Behavior}

Patients' intention to quit smoking was dichotomized $(0=$ no intention to quit within 6 months and $1=$ intention to quit within 6 months). Smoking patients were sent a postal questionnaire 9 months after the GP training in order to assess long-term smoking abstinence rates. Because patients visit their GP on average four times per year, we assumed that most smokers in the baseline group revisited their GP in this 9-month period and as a consequence were exposed to a trained GP (intervention) or nontrained GP (control) (Jurling et al., 2013). Therefore, we included smokers from both the baseline and postintervention group in the follow-up analyses. We examined self-reported 7-day point prevalence abstinence and continuous abstinence

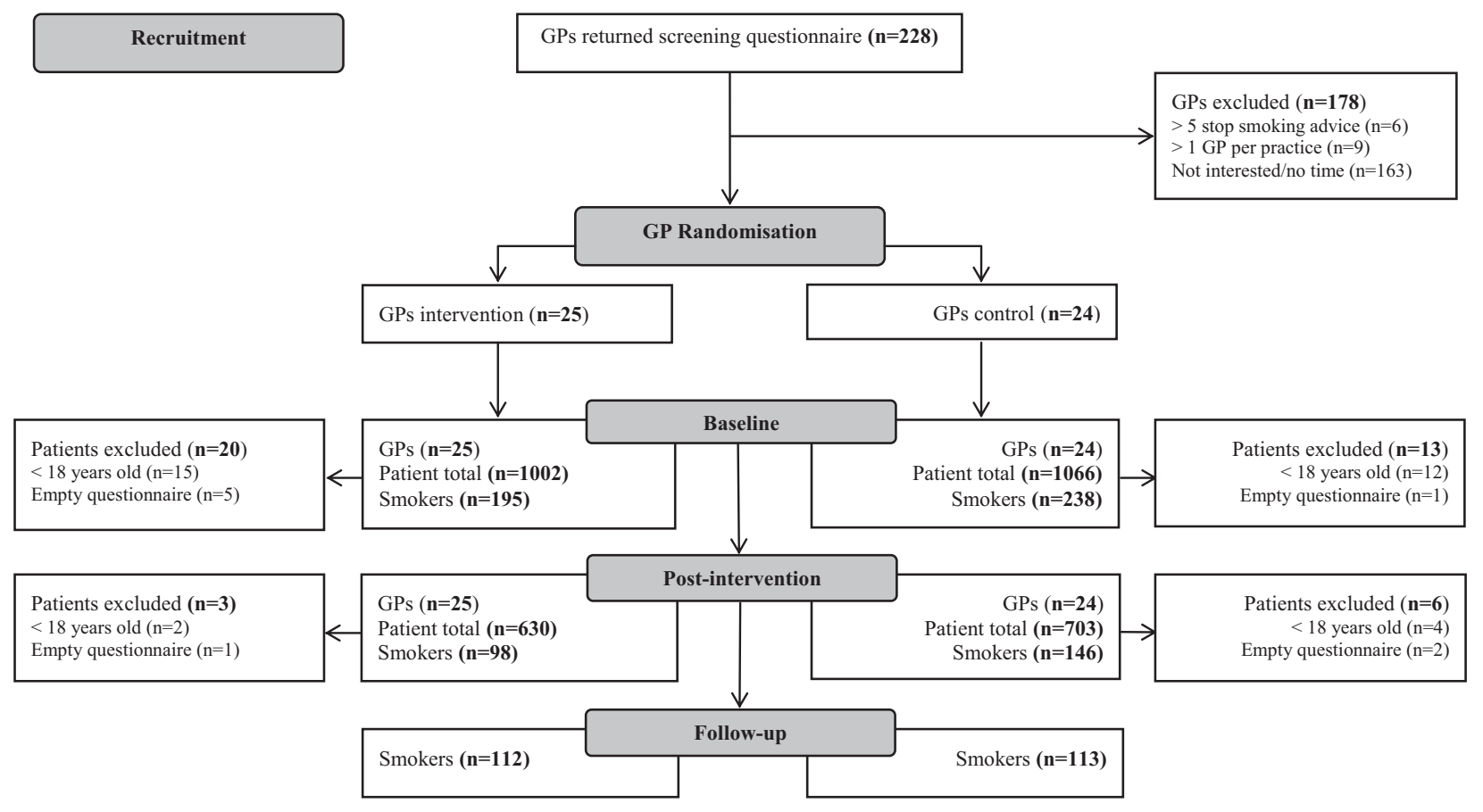

Figure 1. Flowchart of the intervention study. 
(Smit, de Vries, \& Hoving, 2012). In total, 225 smokers completed the 9-month follow-up questionnaire (33.7\%). Of these responders, 112 smokers consulted a GP in the intervention group (70 at baseline [35.9\%] and 42 postintervention [42.9\%]) and 113 smokers consulted a GP in the control group (72 at baseline [30.3\%] and 41 postintervention [28.1\%]).

\section{Sample Size}

Assuming that $21 \%$ of the Dutch adult smokers currently receive a stop-smoking advice from their GP (de Korte et al., 2010), to detect a doubled proportion of smoking patients receiving a stop-smoking advice from their GP, with a power of $80 \%$ (assuming an item characteristic curves of 0.013 and a design effect of 1.104 based on 25 clusters; Lennox et al., 1998), 112 smoking patients per group were required.

\section{Statistical Analyses}

We compared GP characteristics and practice characteristics between the intervention and control group using the chi-square test and independent samples $t$-test for dichotomous and continuous data, respectively. In addition, characteristics of patients in the intervention and control group were compared at baseline and postintervention. The impact of the training on GP-reported outcomes was assessed using linear regression analyses, adjusting for values at baseline. Missing data were imputed according to the last observation carried forward method, assuming that the outcome data did not change postintervention (Streiner \& Geddes, 2001). The impact of the training on GP smoking cessation activities reported by patients was analyzed using generalized estimating equations (GEE) in order to adjust for clustering. In addition, GEE was used to assess smoking abstinence rates of patients at follow-up. Smokers lost to follow-up were treated as not refraining from smoking at follow-up (West, Hajek, Stead, \& Stapleton, 2005).

\section{RESULTS}

\section{GP Cessation Counseling}

\section{General Practitioners}

None of the GP and practice characteristics showed a significant difference between the intervention and control condition (Table 1). With regard to demographics, the sample was similar to the average Dutch GP population (Hingstman \& Kenens, 2010). After adjustment for baseline values, we found a difference for the GP-reported mean number of stop-smoking advices provided per day postintervention (difference 0.56 advice per day; 95\% CI $=0.13-0.98$ ) (Table 2). There was no significant difference in the mean number of times GPs asked smokers about smoking status, referred for behavioral support, and prescribed pharmacological aids.

\section{Patients}

Table 3 reports the characteristics of patients at baseline, postintervention, and at follow-up. At baseline, more patients in the control group reported a chronic airway disease compared to the intervention group ( $15.4 \%$ vs. $12.4 \%$; $p=.03$ ). At postintervention, patients in the control group were younger, more often reported a non-Dutch cultural background and being a smoker (Table 3). After adjustment for clustering effects and patient background characteristics, a time $\times$ condition interaction was found for patients' report of being asked about smoking status $(O R=1.94,95 \% C I=1.43-2.60)$ (Table 2); patients

Table 1. Background Characteristics of Participating GPs and Practices

\begin{tabular}{|c|c|c|}
\hline & Intervention $(n=25)$ & Control $(n=24)$ \\
\hline \multicolumn{3}{|l|}{ GP characteristics } \\
\hline Gender, male & $16(64 \%)$ & $12(50 \%)$ \\
\hline Cultural background, Dutch & $24(96 \%)$ & $22(92 \%)$ \\
\hline Years of employment, $>10$ years & $19(76 \%)$ & $19(79.2 \%)$ \\
\hline \multicolumn{3}{|l|}{ Smoking status } \\
\hline Smoker & $0(0 \%)$ & $2(8.3 \%)$ \\
\hline Ex-smoker & $8(32 \%)$ & $7(29.2 \%)$ \\
\hline Previous training in SCC & $11(44 \%)$ & $8(33.3 \%)$ \\
\hline Age in years $(M, S D)$ & $49.9(8.1)$ & $51.3(8)$ \\
\hline Patients seen per week $(M, S D)$ & $115.8(39.8)$ & $109.5(46.7)$ \\
\hline Hours of work per week $(M, S D)$ & $38.3(9.0)$ & $38.1(10.4)$ \\
\hline \multicolumn{3}{|l|}{ Practice characteristics } \\
\hline \multicolumn{3}{|l|}{ Type of practice } \\
\hline Single handed & $12(48 \%)$ & $10(41.7 \%)$ \\
\hline Duo & $6(24 \%)$ & $9(37.5 \%)$ \\
\hline Group & $5(20 \%)$ & $2(8.3 \%)$ \\
\hline Health care centre & $2(8 \%)$ & $3(12.5 \%)$ \\
\hline \multicolumn{3}{|l|}{ Number of practice nurses } \\
\hline None & $1(4 \%)$ & $3(12.5 \%)$ \\
\hline One practice nurse & $17(68 \%)$ & $16(66.7 \%)$ \\
\hline Two or more practice nurses & $7(28 \%)$ & $5(20.8 \%)$ \\
\hline Previous training in SCC practice nurse & $19(76 \%)$ & $14(58.3 \%)$ \\
\hline
\end{tabular}

Note. GP = general practitioner; $\mathrm{SCC}=$ smoking cessation care. Differences were examined using chi-square tests for dichotomous variables and independent samples $t$-tests for continuous variables. 


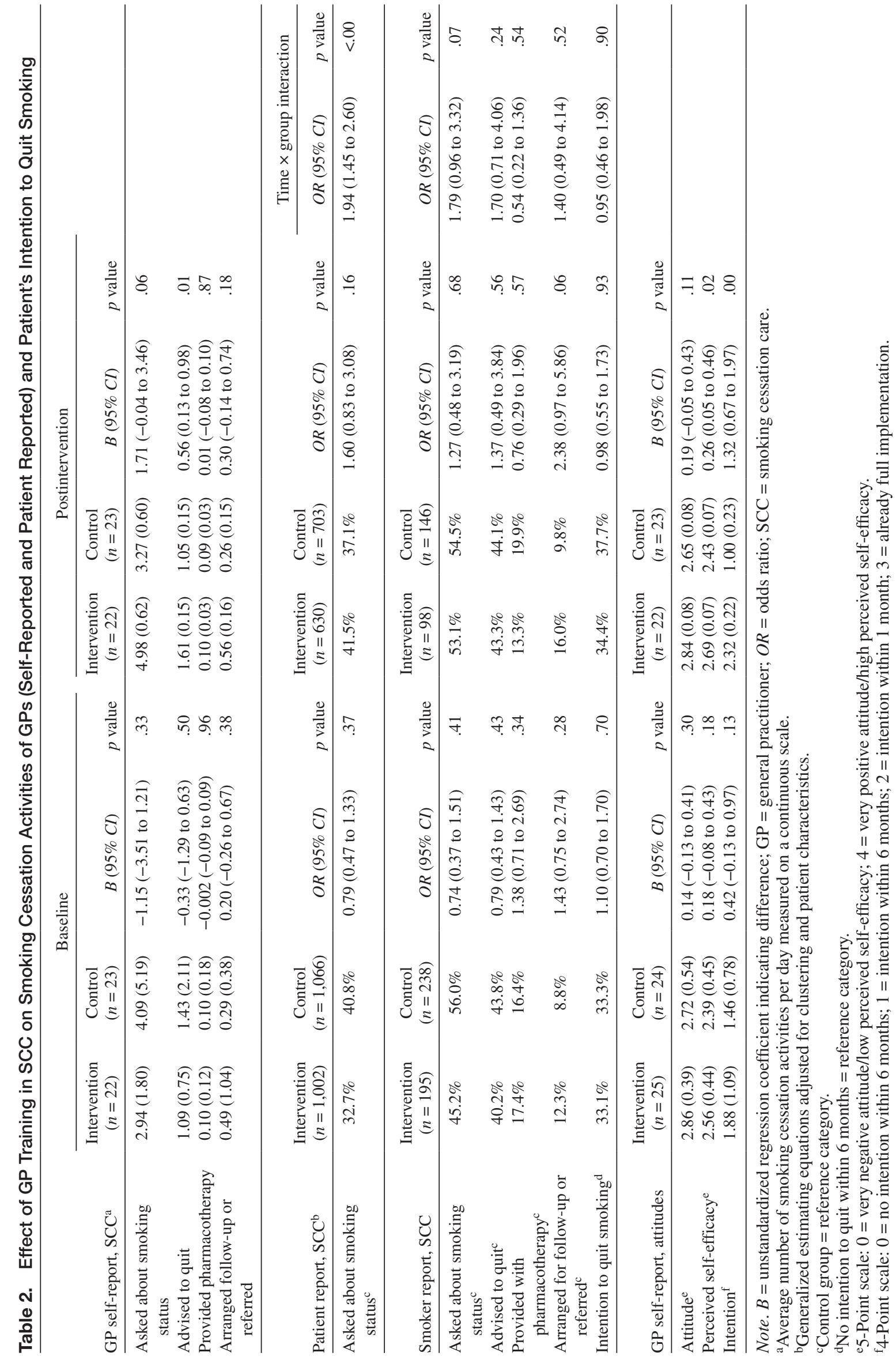


Table 3. Characteristics of Participating Patients at Baseline, Postintervention, and 9-Month Follow-up

\begin{tabular}{|c|c|c|c|c|c|c|c|c|c|}
\hline & \multicolumn{3}{|c|}{ Baseline $(n=2,068)$} & \multicolumn{3}{|c|}{ Postintervention $(n=1,333)$} & \multicolumn{3}{|c|}{ 9-Month follow-up $\left(n=225^{\mathrm{a}}\right)$} \\
\hline & $\begin{array}{c}\text { Intervention, } \\
n=1,002 \\
(48.5 \%)\end{array}$ & $\begin{array}{c}\text { Control, } \\
n=1,066 \\
(51.5 \%)\end{array}$ & $\begin{array}{c}p \\
\text { value }\end{array}$ & $\begin{array}{c}\text { Intervention, } \\
n=630 \\
(47.3 \%)\end{array}$ & $\begin{array}{l}\text { Control, } \\
n=703 \\
(52.7 \%)\end{array}$ & $\begin{array}{c}p \\
\text { value }\end{array}$ & $\begin{array}{c}\text { Intervention, } \\
n=112 \\
(49.8 \%)\end{array}$ & $\begin{array}{l}\text { Control, } \\
n=113 \\
(50.2 \%)\end{array}$ & $\begin{array}{c}p \\
\text { value }\end{array}$ \\
\hline $\begin{array}{l}\text { Age in years, } M \\
(S D)\end{array}$ & $52.9(16.7)$ & $52.2(17.4)$ & $n s$ & $54.0(16.2)$ & $52.3(17.3)$ & 0.01 & $51.7(14.9)$ & $48.9(14.3)$ & $n s$ \\
\hline Gender, men & $374(37.3 \%)$ & $425(39.9 \%)$ & $n s$ & $282(44.8 \%)$ & $278(39.5 \%)$ & $n s$ & $62(55.9 \%)$ & $45(40.2 \%)$ & .02 \\
\hline $\begin{array}{l}\text { Cultural back- } \\
\text { ground, Dutch }\end{array}$ & $918(91.6 \%)$ & $933(87.5 \%)$ & $n s$ & $586(93.0 \%)$ & $626(89.0 \%)$ & .01 & $111(99.1 \%)$ & $106(94.6 \%)$ & $n s$ \\
\hline \multicolumn{10}{|l|}{ Education level } \\
\hline High & $375(37.4 \%)$ & $401(37.6 \%)$ & $n s$ & $250(39.7 \%)$ & $294(41.8 \%)$ & $n s$ & $41(36.6 \%)$ & $34(30.4 \%)$ & $n s$ \\
\hline Medium & $356(35.5 \%)$ & $349(32.7 \%)$ & $n s$ & $203(32.2 \%)$ & $215(30.6 \%)$ & $n s$ & $37(33.0 \%)$ & $41(36.6 \%)$ & $n s$ \\
\hline Low & $224(22.4 \%)$ & $242(22.7 \%)$ & $n s$ & $145(23.0 \%)$ & $162(23.1 \%)$ & $n s$ & $33(29.5 \%)$ & $35(31.2)$ & $n s$ \\
\hline \multicolumn{10}{|l|}{ Physical condition } \\
\hline $\begin{array}{l}\text { Chronic } \\
\text { airways disease }\end{array}$ & $124(12.4 \%)$ & $164(15.4 \%)$ & .03 & $73(11.6 \%)$ & $78(11.1 \%)$ & $n s$ & $20(17.9 \%)$ & $22(19.5 \%)$ & $n s$ \\
\hline Diabetes & $73(7.3 \%)$ & $90(8.4 \%)$ & $n s$ & $42(6.7 \%)$ & $60(8.2 \%)$ & $n s$ & $11(9.8 \%)$ & $8(7.1 \%)$ & $n s$ \\
\hline $\begin{array}{l}\text { Cardiovascular } \\
\text { disease }\end{array}$ & $125(12.5 \%)$ & $108(10.1 \%)$ & $n s$ & $78(12.4 \%)$ & $84(12.0 \%)$ & $n s$ & $17(15.2 \%)$ & $8(7.1 \%)$ & $n s$ \\
\hline Pregnant & $5(0.5 \%)$ & $7(0.7 \%)$ & $n s$ & $3(0.5 \%)$ & $6(0.9 \%)$ & $n s$ & $1(0.9 \%)$ & $0(0.0 \%)$ & $n s$ \\
\hline Smoker & $195(19.5 \%)$ & $238(22.3 \%)$ & $n s$ & $98(15.6 \%)$ & $146(20.8 \%)$ & .01 & & & \\
\hline
\end{tabular}

Note. $n s=$ not significant. Differences were examined using chi-square tests for dichotomous variables and independent samples $t$-tests for continuous variables

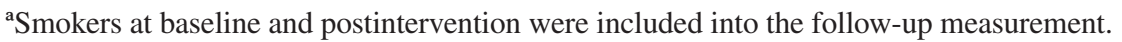

in the intervention group who visited their GP postintervention reported being asked about their smoking status more often than patients who visited their GP prior to the training. We found no effect on patient's report of being advised to quit smoking, being prescribed pharmacotherapy, or being referred for behavioral support (Table 2).

\section{GPs' Attitudes, Self-Efficacy, and Intention}

We found an effect of the training on GPs' perceived selfefficacy and intention toward implementing SCC (Table 2).

\section{Patients' Intention to Quit and Smoking Abstinence}

After adjustment for clustering effects and patient background characteristics, we found no effects of the GP training on smokers' intention to quit (Table 2).

Nine months after the GP training, more patients in the intervention group (baseline and postintervention) completed the follow-up questionnaire compared to patients in the control group (38.2\% vs. $29.4 \% ; p=.02)$. We compared patients who completed the follow-up questionnaire with patients who did not complete the questionnaire. The patients did not differ on the background characteristics they filled out in the first questionnaire (age, gender, cultural background, and educational level). Also, responders and nonresponders did not differ on the number of times they reported being asked about their smoking behavior, were advised to quit, were prescribed pharmacotherapy, or were referred for behavioral counseling during the GP visit, as indicated in the first questionnaire. After controlling for clustering effects and patient background characteristics, $26.8 \%$ of patients in the intervention group reported not having smoked during the past 7 days and $10.8 \%$ refrained from smoking since they completed the first questionnaire (Table 4). In the control group, $25.0 \%$ and $7.1 \%$ of the patients reported 7 -day point prevalence abstinence and continuous abstinence, respectively. We did not find an effect on long-term patient smoking behavior (Table 4). Also, when analyzing responders of the baseline and postintervention group separately, no effect of the GP training on long-term smoking abstinence was found (data not shown).

We performed a sensitivity analysis using the conservative assumption that nonresponders did not change their behavior and still smoked at follow-up (West et al., 2005). This analysis did not change the findings on long-term patients smoking abstinence rates (Table 4).

\section{DISCUSSION}

\section{Major Findings}

This study evaluated the effectiveness of a low-intensity, practice-tailored training in SCC for GPs, addressing both personal and organizational barriers that arise during the implementation of these counseling activities. After the training, we found significant differences between trained and untrained GPs on the frequency they asked about smoking (according to the patients) and gave advice to quit (according to the GPs themselves).

However, we did not find an effect on the arrangement of follow-up support, neither on provision of pharmacological therapy nor on referrals for behavioral support. In addition, we found no effects on patients' intention to stop smoking after GP consultation and long-term cessation rates.

\section{Study Findings Compared to Previous Research}

Our training managed to increase the frequency at which patients reported being asked about smoking and at which GPs reported the provision of stop-smoking advices. Compared to several other training programs that did not find an increase in these counseling 
Nicotine \& Tobacco Research

Table 4. Effect of GP Training in Smoking Cessation Care on Patient Smoking Behavior at 9-Month Follow-up With Different Assumptions About Smoking Behavior of Nonresponders

\begin{tabular}{|c|c|c|c|c|}
\hline & Intervention $(n=112)$ & Control $(n=113)$ & OR $(95 \% C I)^{\mathrm{a}}$ & $p$ value \\
\hline \multicolumn{5}{|l|}{$\begin{array}{l}\text { Percentage of nonsmokers, } \\
\text { not including nonresponders }\end{array}$} \\
\hline Point prevalence abstinence & $26.8 \%$ & $25.0 \%$ & 1.07 (0.57 to 2.00$)$ & .89 \\
\hline \multirow[t]{2}{*}{ Continuous abstinence } & $10.8 \%$ & $7.1 \%$ & $1.62(0.60$ to 4.34$)$ & .34 \\
\hline & Intervention $(n=293)$ & Control $(n=384)$ & OR $(95 \% C I)^{\mathrm{a}}$ & $p$ value \\
\hline \multicolumn{5}{|c|}{$\begin{array}{l}\text { Percentage of nonsmokers, } \\
\text { assuming that all nonresponders smoke }\end{array}$} \\
\hline Point prevalence abstinence & $10.2 \%$ & $7.3 \%$ & $1.33(0.77$ to 2.31$)$ & .30 \\
\hline Continuous abstinence & $4.1 \%$ & $2.1 \%$ & $1.93(0.77$ to 4.89$)$ & .16 \\
\hline
\end{tabular}

Note. $\mathrm{GP}=$ general practitioner; $O R=$ odds ratio. Generalized estimating equations adjusted for clustering effects and patient characteristics.

${ }^{\mathrm{a} C o n t r o l}$ group $=$ reference category .

activities, this is a hopeful outcome (Cornuz et al., 2002; Hymowitz, Schwab, Haddock, Pyle, \& Meshberg, 2006; Joseph et al., 2004). However, we found relatively small rates of smokers for whom GPs had arranged referral and follow-up; other studies found rates of behavioral follow-up ranging from $25 \%$ to $59 \%$ and pharmacological prescriptions from $14 \%$ to $37 \%$ (Anderson \& Jane-Llopis, 2004; Cornuz et al., 2002; Hymowitz, Schwab, Haddock, Pyle, \& Meshberg, 2005; Hymowitz et al., 2006; Joseph et al., 2004).

With regard to the long-term effect of the GP training on patients' smoking behavior, a recent meta-analysis of 14 studies found comparable long-term quit rates as a result of training health professionals in SCC (Carson et al., 2012). However, the majority of the individual studies within this meta-analysis did not confirm statistical significance between quit rates in the intervention and control group, which is in line with our finding.

Although our data suggest that trained GPs more often advised smokers to quit, they failed to increase referral rates and the intention to quit of smokers. This might explain the lack of longterm results. A study of McRobbie, Hajek, Feder, and Eldridge (2008) has shown the effectiveness of a brief training session addressing skills for referral of smokers on the number of GP referrals to evidence-based cessation support. In addition, more and more studies show the increasing role and effectiveness of in-practice cessation support delivered by practice nurses (Hall, Vogt, \& Marteau, 2005; Hoving, Mudde, \& de Vries, 2006; Sheffer, Barone, \& Anders, 2011; Smit, 2012; Zwar, Richmond, Forlonge, \& Hasan, 2011). Moreover, referring and connecting smokers to evidence-based quitlines is likely to increase smoking cessation (Borland et al., 2008; Vidrine et al., 2013).

\section{Strengths and Limitations}

Some limitations with regard to the study design should be considered when interpreting the results of our study. First, the exact response rate of patients who completed the questionnaire at baseline and postintervention is unknown. Reasons for nonresponse might be attributed to GPs who did not hand over the patient questionnaires or to patients who forgot or were unwilling to complete the questionnaire.

Second, participating GPs relatively often advised their patients to quit at baseline $(40.2 \%$ and $43.8 \%$, respectively, compared to only $21 \%$ found in another Dutch study (12)).
An explorative analysis showed that the GPs' awareness of the aim of the intervention and completing tracking lists regarding smoking cessation counseling might make them more prone to ask about smoking compared to GPs that did not complete tracking lists and were unaware of the study topic (data not shown). Despite this possible priming effect, we found an additional significant effect of the training on the number of times patients who were asked about their smoking status (patient reported) and advised to quit (GP reported).

A third limitation is the fact that smoking abstinence at follow-up was self-reported and lacked biochemical verification due to financial constraints. In addition, a large number of patients were lost to follow-up $(66.4 \%)$, especially in the control group $(69.9 \%)$. Attrition is common in lifestyle intervention trials, which may affect the study power, cause bias, and threaten generalizability (Fewtrell et al., 2008).

Fourth, the different sources were slightly inconsistent. On the one hand, GPs reported an increase in the number of stop-smoking advices. On the other hand, patients only reported a significant increase in the number of times they were asked about their smoking status. This discrepancy is in line with other studies, reporting a lack of agreement between patient and provider surveys when measuring tobacco counseling actions (Conroy et al., 2005; Mant, Murphy, Rose, \& Vessey, 2000; Szatkowski, McNeill, Lewis, \& Coleman, 2011; Ward \& Sanson-Fisher, 1996). This might be explained by patients' perception of a stop-smoking advice as being embedded in a general discussion about smoking behavior and therefore have escaped their attention. This could have led to recall bias and may have contributed to the lack of effect on patients' motivation to quit and long-term smoking cessation. Finally, a minority of the participating GPs did not have direct access to smoking cessation programs of (trained) practice nurses during the study period, which may have contributed to the lack of effect on GPs' referrals for behavioral cessation support.

Nevertheless, the major strength is the pragmatic nature of this study (a low-intensity and pragmatic training method) in a specific setting (GP practice), tested in a cluster-randomized controlled trial preventing contamination between GPs, with outcome measures being assessed on both short-term GP and long-term patient level. 


\section{CONCLUSIONS}

Our low-intensity, practice-tailored training for GPs in the implementation of asking patients' smoking status, advising smokers to quit, and arranging referral and follow-up does not lead to an increased patient access to more intensive smoking cessation support. Future training methods should also include practice nurses and focus on the GPs' role as gatekeeper for referring or connecting smokers to cessation support, such as quitlines and practice nurses. This approach is likely to ensure pharmacological and behavioral cessation support and increase patient abstinence rates.

\section{FUNDING}

This study was performed under MIRO, a national program for optimizing smoking cessation. MIRO is an initiative of Pfizer and Caphri. This project is supported by an unrestricted grant from Pfizer and Caphri.

\section{DECLARATION OF INTERESTS}

None declared.

\section{REFERENCES}

Anderson, P., \& Jane-Llopis, E. (2004). How can we increase the involvement of primary health care in the treatment of tobacco dependence? A meta-analysis. Addiction, 99, 299312. doi:10.1111/j.1360-0443.2003.00672.x

Baskerville, N. B., Liddy, C., \& Hogg, W. (2012). Systematic review and meta-analysis of practice facilitation within primary care settings. Annals of Family Medicine, 10, 63-74. doi:10.1370/afm.1312

Berndt, N. C., Bolman, C., de Vries, H., Segaar, D., van Boven, I., \& Lechner, L. (2013). Smoking cessation treatment practices: recommendations for improved adoption on cardiology wards. Journal of Cardiovascular Nursing, 28, 35-47. doi:10.1097./JCN.0b013e318231f424

Borland, R., Balmford, J., Bishop, N., Segan, C., Piterman, L., McKay-Brown, L., \& Tasker, C. (2008). In-practice management versus quitline referral for enhancing smoking cessation in general practice: a cluster randomized trial. Family Practice, 25, 382-389. doi:10.1093/fampra/cmn046

Carson, K. V., Verbiest, M. E. A., Crone, M. R., Brinn, M. P., Estermann, A. J., Assendelft, W. J. J., \& Smith, B. J. (2012). Training health professionals in smoking cessation. Cochrane Database Systematic Reviews [online]. doi:10.1002/14651858.CD000214.pub2

Chavannes, N. H., Kaper, J., Frijling, B. D., Van der Laan, J. R., Jansen, P. W. M., Guerrouj, S., \& Wind, L. A. (2007). Dutch College of General Practitioners Guideline for Smoking Cessation. Huisarts Wet, 50, 306-314. Retrieved from www. ncbi.nlm.nih.gov/pubmed/18666661

Conroy, M. B., Majchrzak, N. E., Silverman, C. B., Chang, Y., Regan, S., Schneider, L. I., \& Rigotti, N. A. (2005). Measuring provider adherence to tobacco treatment guidelines: a comparison of electronic medical record review, patient survey, and provider survey. Nicotine \& Tobacco Research, 7, 35-43. doi:10.1080/14622200500078089

Cornuz, J., Humair, J. P., Seematter, L., Stoianov, R., van Melle, G., Stalder, H., \& Pecoud, A. (2002). Efficacy of resident training in smoking cessation: a randomized, controlled trial of a programme based on application of behavioural theory and practice with standardized patients. Annals of Internal Medicine, 136, 429-437. Retrieved from http://annals.org/ article. aspx .articleid $=715177$

Crone, M. R., Willemsen, M. C., van Soelen, P., Reijneveld, R. A., Hira Sing, R. A., \& Paulussen, T. G. W. M. (2006). Sustainability of the prevention of passive infant smoking within well-baby clinics. Health Education and Behaviour, 33, 178-196. Retrieved from http://heb.sagepub.com/content/33/2/178.full.pdf+html

de Korte, D., Nagelhout, G. E., \& Willemsen, M. C. (2010). Smoking cessation advisement in Dutch general practice: 2001-2009. The Hague, The Netherlands: STIVORO-for a smoke-free future. Retrieved from http://stivoro.nl/wp-content/uploads/themapublicaties/ stoppenmetrokenadviezen/Themapublicatie $\% 20$ Stoppenmetrokenadvisering $\% 20$ door $\% 20$ huisartsen $\% 20$ in $\% 20$ Nederland\%202001\%202009.pdf

de Korte, D., van Schayck, O. C. P., van Spiegel, P., Kaptein, A. A., Sachs, A., Rutten-van Mölken, M., \& Asin, J. (2010). Supporting smoking cessation in healthcare: obstacles in scientific understanding and tobacco addiction management. Health, 2, 1272-1279. doi:10.4236/health.2010.211189

Djalalinia, S., Tehrani, F. R., Malekafzali, H., Dovvom, M. R., Neot, R., \& Peykari, N. (2011). Training of general practitioners about smoking cessation counselling. Journal of the Pakistan Medical Association, 61, 449-452. Retrieved from www.ncbi.nlm.nih.gov/pubmed/22204177

Drossaert, C. H. C., Pieterse, M. E., Seydel, E. R., \& Drenthen, A. (1999). PROMISE: A programmatic application of the minimal intervention strategy (MIS) for smoking cessation in an experimental setting. Evaluation of general practitioners and patients. Retrieved from http://doc.utwente. $\mathrm{nl} / 35860 /$

Ellerbeck, E. F., Ahluwalia, J. S., Jolicoeur, D. G., Gladden, J., \& Mosier, M. C. (2001). Direct observation of smoking cessation activities in primary care practice. Journal of Family Practice, 50, 688-693. Retrieved from www.jfponline.com/ pages .asp?aid=2310

Fewtrell, M. S., Kennedy, K., Singhal, A., Martin, R. M., Ness, A., Hadders-Algra, M., \& Lucas, A. (2008). How much loss to follow-up is acceptable in long-term randomised trials and prospective studies? Archives of Disease in Childhood, 93, 458-461. doi:10.1136/adc.2007.127316

Fiore, M. C., Jaén, C. R., Baker, T. B., Bailey, W. C., Bennett, G., Benowitz, N. L., \& Williams, C. (2008). A clinical practice guideline for treating tobacco use and dependence: 2008 update. A U.S. Public Health Service report. American Journal of Preventive Medicine, 35, 158-176. doi:10.1016/j. amepre.2008.04.009

Fiore, M. C., Wetter, D. W., Bailey, W. C., Blennett, G., Cohen, S. J., Dorfman, S. F., \& Baker, T. B. (1996). The Agency for Health Care Policy and Research Smoking Cessation Clinical Practice Guideline. Journal of the American Medical Association, 275, 1270-1280. Retrieved from http://jama. jamanetwork.com/article. aspx ?articleid $=401129$

Fleuren, M., Wiefferink, K., \& Paulussen, T. (2004). Determinants of innovation within health care organisations: literature review and Delphi study. International Journal for Quality in Health Care, 16, 107-123. Retrieved from http:// intqhc.oxfordjournals.org/content/16/2/107

Hall, S., Vogt, F., \& Marteau, T. M. (2005). A short report: survey of practice nurses' attitudes towards giving smoking cessation advice. Family Practice, 22, 614-616. doi:10.1093/ fampra/cmi082

Harris, M. (2008). The role of primary health care in preventing the onset of chronic disease, with a particular focus on 
the lifestyle risk factors of obesity, tobacco and alcohol. Centre for Primary Health Care and Equity. Retrieved from www.preventativehealth.org.au/internet/preventativehealth/ publishing.nsf/Content/0FBE203C1C547A82CA25752900 0231BF/\$File/commpaper-primary-hlth-care-harris.pdf

Hingstman, L., \& Kenens, R. J. (2010). Figures of the registration of general practitioners. Utrecht, The Netherlands: Netherlands Institute for Health Services Research. Retrieved from www.nivel.nl/sites/default/files/bestanden/cijfers-uitde-registratie-van-huisartsen-peiling-jan-2011.pdf

Hoving, C., Mudde, A. N., \& de Vries, H. (2006). Intention to adopt a smoking cessation expert system within a selfselected sample of Dutch general practitioners. European Journal of Cancer Prevention, 15, 82-86. Retrieved from www.ncbi.nlm.nih.gov/pubmed/?term=Intention+to+adopt $+\mathrm{a}+$ smoking+cessation+expert+system+within+a+self-sele cted+sample+of+Dutch+general+practitioners

Hymowitz, N., Schwab, J., Haddock, C. K., Pyle, S., \& Meshberg, S. (2005). The pediatricy residency training on tobacco project: baseline findings from patient tobacco survey. Preventive Medicine , 41, 159-166. Retrieved from www. sciencedirect.com/science/article/pii/S0091743504005596

Hymowitz, N., Schwab, J., Haddock, C. K., Pyle, S., \& Meshberg, S. (2006). The pediatric resident training on tobacco project: interim findings. Journal of the National Medical Association, 98, 190-203. Retrieved from www. ncbi.nlm.nih.gov/pmc/articles/PMC2595064/

Joseph, A. M., Arikian, N. J., An, L. C., Nugent, S. M., Sloan, R. J., \& Pieper, C. F. (2004). Results of a randomized controlled trial of intervention to implement smoking guidelines in Veterans Affairs medical centres: increased use of medications without cessation benefit. Medical Care, 42, 11001110. Retrieved from www.ncbi.nlm.nih.gov/pubmed/?term $=$ Results + of $+\mathrm{a}+$ randomized + controlled + trial + of + interventi on+to+implement+smoking+guidelines+in+Veterans+Affa irs+medical+centres $\% 3 \mathrm{~A}+$ increased+use+of+medications+ without+cessation+benefit

Jurling, B., Koster, L., Batterink, M., Vunderink, L., Schippers, M., \& Karsson, B. (2013). Practice costs and income research in primary care. The Dutch Healthcare Authority. Retrieved from www.nza.nl/104107/138040/Significant praktijkkosten-_en_inkomensonderzoek_huisartsenzorg.pdf

Koolhaas, C. (2005). Campaign 'More general practitioners go for less' (Report No. E1283). Amsterdam, The Netherlands: TNS NIPO. Retrieved from http://stivoro.nl/ wp-content/uploads/2012/docs/rapporten/stoppenmetroken/ Campagne\%20'Meer\%20huisartsen\%20gaan\%20voor\%20 minder\%20rokers'.pdf

Lennox, A. S., Bain, N., Taylor, N. J., McKie, L., Donnan, P. T., \& Groves, J. (1998). Stages of change training for opportunistic smoking intervention by the primary health care team. Health Education Journal, 57, 140-149. doi:10.1177/001789699805700206

Mant, J., Murphy, M., Rose, P., \& Vessey, M. (2000). The accuracy of general practitioner records of smoking and alcohol use: comparison with patient questionnaires. Journal of Public Health Medicine, 22, 198-201. doi:10.1093/ pubmed/22.2.198

McRobbie, H., Hajek, P., Feder, G., \& Eldridge, S. (2008). A cluster-randomised controlled trial of a brief training session to facilitate general practitioner referral to smoking cessation treatment. Tobacco Control, 17, 173-176. doi:10.1136/ tc. 2008.024802

Mudde, A. N., Willemsen, M. C., Kremers, S., \& de Vries, H. (2000). Measurement instruments for research related to smoking and smoking cessation. The Hague, The Netherlands: STIVORO-for a smoke-free future. Retrieved from http://stivoro.nl/wp-content/uploads/2012/docs/rapporten/ diversen/meetinstrumenten_3.pdf

Oxman, A. D., Thomson, M. A., Davis, D. A., \& Haynes, R. B. (1995). No magic bullets: a systematic review of 102 trials of interventions to improve professional practice. Canadian Medical Association Journal, 153, 1423-1431. Retrieved from www.ncbi.nlm.nih.gov/pmc/articles/ PMC1487455/?page $=1$

Pieterse, M. E., Seydel, E. R., de Vries, H., Mudde, A. N., \& Kok, G. J. (2001). Effectiveness of a minimal contact smoking cessation program for Dutch general practitioners: a randomized controlled trial. Preventive Medicine, 32, 182-190. doi:10.1006/pmed.2000.0791

Puschel, K., Thompson, B., Coronado, G., Huang, Y., Gonzalez, L., \& Rivera, S. (2008). Effectiveness of a brief intervention based on the ' $5 \mathrm{~A}$ ' model for smoking cessation at the primary care level in Santiago, Chile. Health Promotion International, 23, 240-250. doi:10.1093./heapro./dan010

Quinn, V. P., Stevens, V. J., Hollis, J. F., Rigotti, N. A., Solberg, L. I., Gordon, N., \& Zapka, J. (2005). Tobaccocessation services and patient satisfaction in nine nonprofit HMOs. American Journal Preventive Medicine, 29, 77-84. doi:10.1016/j.amepre.2005.04.006

Rollnick, S., \& Miller, W. R. (1995). What is motivational interviewing? Behavioural and Cognitive Psychotherapy, 23, 325-334. doi:10.1017/S135246580001643X

Segaar, D. (2009). STIMEDIC method for smoking cessation: an effective minimal contact program for smoking cessation in Dutch health care. Utrecht, The Netherlands: Hollandse Meesters BNO. Retrieved from www.loketgezondleven. nl/i-database/interventies/s/3875/

Sheffer, C. E., Barone, C., \& Anders, M. E. (2011). Training nurses in the treatment of tobacco use and dependence: preand post-training results. Journal of Advanced Nursing, 67, 176-183. doi:10.1111/j.1365-2648.2010

Smit, E. S. (2012). Motivating smokers to quit. Effectiveness and feasibility of a web-based multiple tailored smoking cessation programme and tailored counselling by practice nurses. Maastricht University. Retrieved from http://phdthesis.nl/sites/default/files/Thesis_Smit_1.pdf

Smit, E. S., de Vries, H., \& Hoving, C. (2012). Effectiveness of a web-based multiple tailored smoking cessation program: a randomized controlled trial among Dutch adult smokers. Journal of Medical Internet Research, 14. doi:10.2196/ jmir. 1812

Stead, M., Angus, K., Holme, I., Cohen, D., \& Tait, G. (2009). Factors influencing European GPs' engagement in smoking cessation: a multi-country literature review. British Journal of General Practice, 59, 682-690. doi:10.3399/ bjgp09X454007

Stead, L. F., Bergson, G., \& Lancaster, T. (2008). Physician advice for smoking cessation. Cochrane Database Systematic Reviews [online]. doi:10.1002/14651858.CD000165.pub3

Stop Smoking Partnership. (2009). The Dutch national guideline for the treatment of tobacco addiction. Alphen aan den Rijn, The Netherlands: Van Zuiden Communications B.V. Retrieved from http://www.partnershipstopmetroken.nl/ richtlijn-2/

Streiner, D., \& Geddes, J. (2001). Intention to treat analysis in clinical trials when there are missing data. Evidence Based Mental Health, 4, 70-71. doi:10.1136/ebmh.4.3.70

Szatkowski, L., McNeill, A., Lewis, S., \& Coleman, T. (2011). A comparison of patient recall of smoking cessation advice with advice recorded in electronic medical records. BMC Public Health, 11, 1-4. doi:10.1186/1471-2458-11-291

Takahashi, K., Saso, H., Saka, H., Saso, H., Iwata, M., Hashimoto, I., \& Hamajima, N. (2006). A pilot study on inducement of smoking cessation by a simple $5 \mathrm{~A}$ (asking, advice, assess, 
Training for GPs in reducing the implementation gap of smoking cessation care

assist, and arrange) approach at outpatient clinics. Asian Pacific Journal of Cancer Prevention, 7, 131-135. Retrieved from www.apocpcontrol.org/page/apjcp_issues_view.php?sid $=$ Entrez:PubMed\&id=pmid:16629531\&key=2006.7.1.131

The Royal Australian College of General Practitioners. (2011). Supporting smoking cessation: a guide for health professionals. Author. Retrieved from www.racgp.org.au/ your-practice/guidelines/smoking-cessation/

Tremblay, M., Gervais, A., Lacroix, C., O’Loughlin, J., Makni, H., \& Paradis, G. (2001). Physicians taking action against smoking: an intervention program to optimise smoking cessation counselling by Montreal general practitioners. Canadian Medical Association Journal, 165, 601-607. Retrieved from www.sciencedirect.com/science/article/pii/S0091743501909375

Twardella, D., \& Brenner, H. (2005). Lack of training as a central barrier to the promotion of smoking cessation: a survey among general practitioners in Germany. European Journal of Public Health, 15, 140-145. doi:10.1093/eurpub/ cki123

Vidrine, J. I., Shete, S., Cao, Y., Greisinger, A., Harmonson, P., Sharp, B., \& Wetter, D. W. (2013). Ask-advise-connect: a new approach to smoking treatment delivery in health care settings. JAMA Internal Medicine, 173, 458-464. doi:10.1001./jamainternmed.2013.3751

Vogt, F., Hall, S., \& Marteau, T. M. (2005). General practitioners' and family physicians' negative beliefs and attitudes towards discussing smoking cessation with patients: a systematic review. Addiction, 100, 1423-1431. doi:10.1111/j.1360-0443.2005.01221.X

Ward, J., \& Sanson-Fisher, R. (1996). Accuracy of patient recall of opportunistic smoking cessation advice in general practice. Tobacco Control, 5, 110-113. doi:10.1136/tc.5.2.110

West, R., Hajek, P., Stead, L., \& Stapleton, J. (2005). Outcome criteria in smoking cessation trials: proposal for a common standard. Addiction, 100, 299-303. doi:10.1111/j.1360-0443.2004.00995.x

Zwar, N. A., \& Richmond, R. L. (2006). Role of the general practitioner in smoking cessation. Drug and Alcohol Review, 25, 21-26. doi:10.1080/09595230500459487

Zwar, N. A., Richmond, R. L., Forlonge, G., \& Hasan, I. (2011). Feasibility and effectiveness of nurse-delivered smoking cessation counselling combined with nicotine replacement in Australian general practice. Drug Alcohol Review, 30, 583-588. doi:10.1111/j.1465-3362.2010.00243.x 